\title{
Functional characterization of naturally occurring transglutaminase 2 mutants implicated in early-onset type 2 diabetes
}

\author{
Neil W Salter ${ }^{1}$, Sudharsana R Ande ${ }^{2 \star}$, Hoa K Nguyen ${ }^{1 *}$, B L Grégoire Nyomba ${ }^{1,2}$ \\ and Suresh Mishra ${ }^{1,2}$ \\ Departments of ${ }^{1}$ Physiology and ${ }^{2}$ Internal Medicine, University of Manitoba, Winnipeg, Manitoba, Canada \\ (Correspondence should be addressed to S Mishra who is now at Diabetes Research Group, University of Manitoba, 843 JBRC/715 McDermot Avenue, \\ Winnipeg, Manitoba, Canada R3E 3P4; Email: mishra@cc.umanitoba.ca) \\ *(S R Ande and H K Nguyen contributed equally to this work)
}

\begin{abstract}
Transglutaminase 2 (TG2) is an enzyme with diverse biological functions. TG2 catalyzes transamidation reactions, has intrinsic kinase activity, and acts as a G-protein in intracellular signaling. TG2 (Tgm2)-null mice are glucose intolerant and have impaired glucose-stimulated insulin secretion (GSIS). Furthermore, three naturally occurring missense mutations in the human TGM2 gene, corresponding to amino acid substitutions of Met330Arg, lle331Asn, and Asn333Ser in the TG2 protein, have been reported and found to be associated with early-onset type 2 diabetes. However, their effect on TG2 function is not fully understood. To determine this, we have reproduced naturally occurring mutations in TG2 using site-directed mutagenesis. Overexpression of Myc-TG2 mutants in INS-1E cells resulted in a reduction of GSIS in comparison with cells overexpressing wild-type Myc-TG2 (WT-TG2). The maximum reduction was found in cells overexpressing Ile331Asn-TG2 (32\%) followed by Met330Arg-TG2 (20\%), and the least in Asn333Ser-TG2 (7\%). Enzymatic analysis revealed that TG2 mutants have impaired transamidation and kinase activities in comparison with WT-TG2. GTP-binding assays showed that TG2 mutants also have altered GTP-binding ability, which is found to be modulated in response to glucose stimulation. Collectively, these data suggest that naturally occurring mutations in TG2 affect transamidation, kinase, and GTP-binding functions of TG2. While reduced insulin secretion, as a result of naturally occurring mutations in TG2, is due to the impairment of more than one biological function of TG2, it is the transamidation function that appears to be impaired during the first phase, whereas the GTP-binding function affects the second phase of insulin secretion.
\end{abstract}

Journal of Molecular Endocrinology (2012) 48, 203-216

\section{Introduction}

Transglutaminase 2 (TG2) is a multi-functional proteinmodifying enzyme (EC 2.3.2.13) that has been mapped to the locus $20 \mathrm{q} 12$ on human chromosome 20 (Gentile et al. 1994). The locus $20 \mathrm{q} 12$ has been identified as a susceptibility locus for non-insulin-dependent type 2 diabetes in linkage studies and is believed to contain more than one susceptibility gene (Ji et al. 1997, Zouali et al. 1997, Ghosh et al. 1999). One such gene is hepatocyte nuclear factor $4 \alpha(H N F 4 A)$. Mutations in the HNF4A gene have been reported to be involved in young-onset type 2 diabetes (Johnson 2007). In addition to $H N F 4 A$, mutations in the TG2 (TGM2) gene have also been implicated in young-onset type 2 diabetes (Bernassola et al. 2002, Porzio et al. 2007). Three heterozygous missense mutations in the $T G 2$ gene, which lead to amino acid changes in the TG2 protein at positions 330, 331, and 333 from methionine to arginine (Met330Arg), isoleucine to asparagine (Ile331Asn), and asparagine to serine
(Asn333Ser) respectively, have been identified in patients with young-onset type 2 diabetes (Bernassola et al. 2002, Porzio et al. 2007). Furthermore, mice lacking $T G 2\left(T G 2^{-/-}\right)$are glucose intolerant and have impaired glucose-stimulated insulin secretion (GSIS) and exhibit a phenotype similar to maturity onset diabetes of the young (MODY), a group of autosomal dominant, single-gene disorders that cause diabetes in young adults or children (Bernassola et al. 2002). The genetic evidences together suggest an important physiological role for TG2 in pancreatic $\beta$-cell function, though the actual mechanism involved is not understood.

A well-known function of TG2 is calcium-dependent transamidation, which is also known as a "protein crosslinking' function, due to the formation of a $\gamma$-glutamyl-e-lysine bond between the side chain of lysine and glutamine residues of two protein molecules (Fesus \& Piacentini 2002). Recently, serotonylation (covalent coupling of serotonin to protein) of small G-proteins in pancreatic $\beta$-cells mediated by the transamidation function of TG2 has been implicated

DOI: 10.1530/JME-11-0064 Online version via http://www.endocrinology-journals.org 
in GSIS (Paulmann et al. 2009). In this paper, the enzyme TG2 placed serotonin on glutamine residue(s) of small GTPases to form a glutamyl amide bond (serotonylation), resulting in the activation of G-proteins (Paulmann et al. 2009). Small GTPases have been known to be involved in insulin secretion from $\beta$-cells (Kajio et al. 2001, Kasai et al. 2005). For example, a small GTPase, Rab3a, has been shown to regulate replenishment of the readily releasable pool of $\beta$-granules at early stages of vesicle transport (Kajio et al. 2001). Furthermore, Rab27a has been reported to act directly in the targeting of $\beta$-granules from the resting pool to the readily releasable pool in the plasma membrane (Kasai et al. 2005).

In addition, we have reported that TG2 has intrinsic kinase activity and phosphorylates a number of proteins including insulin-like growth factor binding protein-3 (IGFBP3; Mishra \& Murphy 2004, Mishra et al. 2006, $2007 a, b)$. We have recently found that IGFBP3 has a role in insulin secretion (Nguyen et al. 2011). Moreover, we have shown that ATP and $\mathrm{Ca}^{2+}$ reciprocally regulate transamidation and kinase activities of TG2 (Mishra \& Murphy 2004). ATP facilitates kinase activity and has an inhibitory effect on transamidation activity, whereas $\mathrm{Ca}^{2+}$ has an opposite effect (Mishra \& Murphy 2004, Mishra et al. 2007a,b). Furthermore, TG2 binds to GTP and functions as a G-protein in cell signaling processes (Baek et al. 2001), and the GTP-binding and transamidation functions of TG2 are inversely associated with each other (Murthy et al. 2002, Begg et al. 2006). Although the transamidation catalytic triad $\left(\mathrm{Cys}^{277}\right.$, $\mathrm{His}^{335}$, and $\left.\mathrm{Asp}^{358}\right)$ and putative GTP/ATP $\left({ }^{169} \mathrm{Gln}-\mathrm{Gly}\right.$ Ser-Ala-Lys ${ }^{173}$ and ${ }^{580}$ Arg-Asp-Leu-Tyr ${ }^{583}$ ) binding loops are located distantly from each other in the primary structure of TG2, they are very close to each other in the secondary structure, as revealed by the crystal structure of TG2 (Murthy et al. 2002, Begg et al. 2006). However, the functional consequences of naturally occurring TG2 mutations on TG2 enzymatic activities and on GTP-binding function have not been characterized yet. Although a role for the transamidation function of TG2 in GSIS has been proposed (Porzio et al. 2007), there is no unequivocal evidence to support this hypothesis. Moreover, the possibility of the involvement of TG2 functions other than the transamidation function was not addressed before. It is possible that these mutations in $T G 2$ affect both transamidation and kinase activities of TG2 in a mutually exclusive or in an inclusive manner. Moreover, it may also affect the GTP-binding ability of TG2 and its function as a G-protein. In this study, we investigated the functional impact of naturally occurring TG2 mutations on TG2 enzymatic activities as well as on the GTP-binding function and their relationship with GSIS in clonal INS-1E pancreatic $\beta$-cells.

\section{Materials and methods}

\section{Reagents}

Cell culture reagents were obtained from American Type Cell Collection (ATCC, Danvers, MA, USA), and heat-inactivated fetal bovine serum and anti-rabbit Alexa Fluor 488 from Invitrogen. Anti-Myc antibody was obtained from Cell Signaling Technology (Danvers, MA, USA), and anti-serotonin antibody and HRPconjugated secondary antibodies were obtained from Santa Cruz Biotechnology. ProFound c-Myc Tag IP/Co-IP Kit and 5-(biotinamido)pentylamine $\left(\mathrm{BPNH}_{2}\right)$ were purchased from Pierce (Rockford, IL, USA) and Ultrasensitive Insulin ELISA kits (mouse and rat) were obtained from Chrystal Chem (Downers Grove, IL, USA). Enhanced chemiluminescence (ECL) reagents and sequencing grade trypsin were purchased from Promega. ATP- and GTP-agarose resins were obtained from Innova Biosciences (Cambridge, UK). Other reagents were purchased from SigmaAldrich or as otherwise stated.

\section{Animals}

TG2 knockout C57BL/6 mice were generously provided by Dr Nikolaos Frangogiannis (Baylor College of Medicine, Houston, TX, USA) with permission from Dr Gerry Melino (University of Leicester, UK). Wildtype (WT) and $T G 2^{-/-}$C57BL/6 mice were housed at the University of Manitoba Central Animal Care Facility. Mice were housed under controlled temperature $\left(21^{\circ} \mathrm{C}\right)$ and light conditions (12 h light:12 h darkness cycle) with ad libitum access to water and a standard diet. The experiments involving mice were performed as approved by the Animal Care Committee of the University of Manitoba.

\section{Isolation of pancreatic islets}

Islets were isolated by collagenase (Roche) digestion of the mouse pancreas as described (Lacy \& Kostianovsky 1967). Once isolated, the islets were cultured in RPMI-1640 medium containing $11 \mathrm{mM}$ glucose, $10 \%$ heat-inactivated fetal bovine serum, and $100 \mu \mathrm{g} / \mathrm{ml}$ penicillin-streptomycin for $24 \mathrm{~h}$ (Nguyen et al. 2011).

\section{Batch incubations}

Batches of four islets were pre-incubated in KrebsRinger bicarbonate (KRB) buffer solution (118.4 mM $\mathrm{NaCl}, 4.7 \mathrm{mM} \mathrm{KCl}, 1.9 \mathrm{mM} \mathrm{CaCl}{ }_{2}, 1.2 \mathrm{mM} \mathrm{MgSO}_{4}$, $1 \cdot 2 \mathrm{mM} \mathrm{KH}_{2} \mathrm{PO}_{4}$, and $25 \mathrm{mM} \mathrm{NaHCO}$ (equilibrated with $\left.5 \% \mathrm{CO}_{2}-95 \% \mathrm{O}_{2}, \mathrm{pH} 7 \cdot 4\right), 0 \cdot 2 \% \mathrm{BSA}$, and $10 \mathrm{mM}$ HEPES) containing $3.3 \mathrm{mM}$ glucose for $30 \mathrm{~min}$. The islets were then incubated for $30 \mathrm{~min}$ in KRB buffer 
containing $16.7 \mathrm{mM}$ glucose. The buffer samples were collected for the insulin assay by ELISA according to the manufacturer's instructions.

\section{Cell culture}

The rat insulinoma cell line INS-1E was a generous gift from Dr Michael Wheeler (University of Toronto, Toronto, ON, Canada) with permission from Prof. Claes Wollheim (University of Geneva, Geneva Switzerland). INS-1E cells were cultured in RPMI-1640 medium supplemented with $10 \%$ heat-inactivated fetal bovine serum, $10 \mathrm{mM}$ HEPES, $1 \mathrm{mM}$ sodium pyruvate, $50 \mu \mathrm{M}$ $\beta$-mercaptoethanol, $100 \mu \mathrm{g} / \mathrm{ml}$ penicillin-streptomycin (Gauthier et al. 2009, Lee et al. 2010).

\section{TG2 constructs and cell transfections}

The pCMV6 vector containing the Myc-tagged human TG2 (Myc-TG2) clone was obtained from Origene Technologies (Rockville, MD, USA). Naturally occurring TG2 mutants and the transamidation-activity dead Cys277Ala-TG2 mutant (as a negative control for transamidation function of TG2) were made using a site-directed mutagenesis kit (Ande et al. 2009a,b) using two complementary oligonucleotide primers containing the desired mutation and Myc-TG2 as the template. The primers used for generating various $T G 2$ mutants are shown in Table 1. The parental strand was removed by DpnI digestion before transformation into Escherichia colistrain DH5 $\alpha$. Authenticity of all constructs was confirmed by DNA sequencing. Transfections with various constructs were performed using FuGENE HD transfection reagent (Roche) according to the manufacturer's instructions (Ande et al. 2009a,b). A consistent transfection efficiency of $40-45 \%$ was obtained using $2 \mu \mathrm{g}$ plasmid DNA/3 $\mu$ l transfection reagent.

\section{Immunoprecipitation}

The ProFound c-Myc Tag IP/Co-IP Kit was used, according to the manufacturer's instructions, to immunoprecipitate the $M y c$-tagged WT and TG2 mutants. For the samples to be used in kinase and transamidation activity assays, rather than subjecting to elution, the protein-bead complexes were resuspended in $50 \mathrm{mM}$ Tris buffer $(\mathrm{pH} \mathrm{7.4)}$ to preserve enzyme activity.

\section{Western blotting}

Cells were rinsed in PBS and collected in lysis buffer (Sigma-Aldrich), containing protease inhibitor cocktail (Ande et al. 2009a,b). The samples were incubated on ice with intermittent vortexing for $30 \mathrm{~min}$, followed by centrifugation at $13000 \mathrm{~g}$ for $10 \mathrm{~min}$. Protein concentrations of the supernatants were determined by the Bradford protein assay with BSA as the standard. SDS-PAGE sample buffer was added to the samples, and the samples were then boiled for $5 \mathrm{~min}$. Proteins were resolved on 10-12\% SDS-PAGE, according to target protein size, and transferred onto nitrocellulose membranes. The membranes were blocked in $5 \%$ milk for $1 \mathrm{~h}$ at room temperature and then incubated with primary antibodies for $1 \mathrm{~h}$ at room temperature or overnight at $4{ }^{\circ} \mathrm{C}$. Membranes were washed three times with TBST wash buffer $(10 \mathrm{mM}$ Tris, $150 \mathrm{mM} \mathrm{NaCl}$, $0.05 \%$ Tween 20 , pH 8.0$)$, and then incubated with either HRP-conjugated secondary antibodies or streptavidin-HRP conjugate for $1 \mathrm{~h}$ at room temperature. Membrane washing steps with TBST were repeated, followed by the addition of ECL reagent. Membranes were exposed to Kodak Biomax MR Film (Sigma) and protein bands were analyzed by densitometry using Scion Image software (Frederick, MD, USA).

\section{In vitro kinase assay}

An in vitro kinase assay was performed in kinase buffer (50 mM Tris-HCl, $\mathrm{pH} 7 \cdot 5,10 \mathrm{mM}$ magnesium chloride, $\left[\gamma^{-32} \mathrm{P}\right]$ ATP $\left.(25 \mu \mathrm{Ci} / \mathrm{ml})\right)$ for $30 \mathrm{~min}$ at $30^{\circ} \mathrm{C}$ as described previously (Mishra \& Murphy 2004, Mishra et al. 2006). The reaction was stopped by the addition of SDS-PAGE sample buffer and the samples were boiled for $5 \mathrm{~min}$. The samples were resolved on SDS-PAGE,

Table 1 Primer sequences used to develop TG2 mutants by site-directed mutagenesis

TG2 mutants

Met330Arg

Ile331Asn

Asn333Ser

Cys277Ala

\section{Primer sequences}

Forward: 5'-GTGACAAGAGCGAGAGGATCTTGAACTTCCAC-3' Reverse: $5^{\prime}$-GTGGAAGTTCCAGATCCTCTCGCTCTTGTCACC-3' Forward: 5'-GACAAGAGCGAGATGAACTGGAACTTCCACTGC-3' Reverse: 5'-GCAGTGGAAGTTCCAGTTCATCTCGCTCTTGTC-3' Forward: 5'-GCGAGATGATCTGGAGCTTCCACTGCTGGGT-3' Reverse: 5'-ACCCAGCAGTGGAAGCTCCAGATCATCTCGC-3' Forward: 5'-GTCAAGTATGGCCAGGCCTGGGTCTTCGCCGC-3' Reverse: 5'-GCGGCGAAGACCCAGGCCTGGCCATACTTGAC-3'

TG2, transglutaminase 2; Met, methionine; Arg, arginine; lle, isoleucine; Asn, asparagine; Ser, serine; Cys, cysteine; Ala, alanine. 
transferred onto nitrocellulose membranes, and analyzed by autoradiography. TG2 protein content in the samples was determined by probing nitrocellulose membranes with a rabbit anti-Myc antibody, which was detected with HRP-conjugated anti-rabbit IgG followed by exposure to ECL.

\section{Transamidation activity measurement}

The Transglutaminase Assay Kit (Sigma) was used, according to the manufacturer's instructions, to evaluate the transamidation activity of WT- and mutant TG2. TG2 protein samples used in the assay were purified by Myc immunoprecipitation (IP) from the cell lysates prepared from INS-1E cells transfected with WT- or mutant TG2 (Brymora et al. 2001).

\section{In situ transamidation activity assay}

INS-1E cells were cultured in $60 \mathrm{~mm}$ tissue culture plates at $60 \%$ confluency. They were then transfected with vectors expressing $M y c$-tagged WT- and mutant $T G 2$ and further cultured for $48 \mathrm{~h}$. Cells were preincubated for $1 \mathrm{~h}$ with $1 \mathrm{mM} \mathrm{BPNH}_{2}$ in standard culture medium (Antonyak et al. 2006). They were then rinsed in PBS and sensitized to glucose for $30 \mathrm{~min}$ in glucosefree standard medium. Cells were rinsed again in PBS, and incubated in medium containing either 3.3 or $16.7 \mathrm{mM}$ glucose for $30 \mathrm{~min}$. They were then lysed and the supernatant was collected for further analysis by western blot.

\section{Insulin secretion assays}

INS-1E cells were cultured and transfected with various $T G 2$ constructs as described above. After $48 \mathrm{~h}$ posttransfection, cells were rinsed with PBS and sensitized to glucose for $30 \mathrm{~min}$ in glucose-free KRB buffer solution. Cells were rinsed again with PBS, and incubated with KRB buffer containing either 3.3 or $16.7 \mathrm{mM}$ glucose for $30 \mathrm{~min}$. KRB buffer was collected and analyzed for insulin content with the Ultra Sensitive Rat Insulin ELISA kit, according to the manufacturer's instructions. Lysates of cells were collected and total protein content was determined. The insulin content of KRB buffer was normalized to the total protein content. Protein content was determined by the Bradford assay (BioRad).

\section{Perifusion of INS-1E spheroidal clusters}

INS-1E cells were cultured in $60 \mathrm{~mm}$ cell culture plates at $60 \%$ confluency and transfected with various TG2 constructs. At 2 days post-transfection, cells were trypsinized and seeded in non-adherent Petri dishes, allowing the formation of INS-1E spheroids as described by Merglen et al. (2004). At $48 \mathrm{~h}$ in culture, 50 spheroids were collected from each dish and expression levels of WT- and mutant TG2 were confirmed by western blot. At $72 \mathrm{~h}, 500$ spheroids were collected from each dish, washed in $3.3 \mathrm{mM}$ glucose/KRB buffer, and were loaded into perifusion chambers. Spheroids were perifused for $10 \mathrm{~min}$ with $3.3 \mathrm{mM}$ glucose/KRB buffer prior to initiating the collection of the effluent. Spheroids were then perifused at $0.3 \mathrm{ml} / \mathrm{min}$ with basal $3.3 \mathrm{mM}$ glucose for $24 \mathrm{~min}$ and $16.7 \mathrm{mM}$ for $30 \mathrm{~min}$, followed by $3.3 \mathrm{mM}$ for $10 \mathrm{~min}$, while the effluent was collected every $2 \mathrm{~min}$, as described for the isolated islets (Nguyen et al. 2011). The collected samples were measured for insulin content as described above.

\section{Fluorescence microscopy}

INS-1E cells were grown on cell culture slides (BD Biosciences, Mississauga, ON, Canada) at $60 \%$ confluency and transfected with various $T G 2$ constructs. At $48 \mathrm{~h}$ post-transfection, cells were washed with PBST (PBS containing $0 \cdot 05 \%$ Tween 20 ) and fixed with $10 \%$ formalin for $20 \mathrm{~min}$ at room temperature. After washing with PBST $(2 \times 5 \mathrm{~min})$, cells were blocked with $1 \%$ BSA for $2 \mathrm{~h}$ at room temperature. Subsequently, the cells were incubated with an anti-Myc antibody (1:200 in 1\% BSA) for $2 \mathrm{~h}$ at room temperature or overnight at $4{ }^{\circ} \mathrm{C}$. The cells were washed three times with PBST, and incubated for $1 \mathrm{~h}$ at room temperature in a solution containing anti-rabbit Alexa Fluor $488(1: 300)$ in 1\% BSA. The cells were then washed with PBST, mounted, and observed under a fluorescence microscope (Ande \& Mishra 2009).

\section{In-gel digestion of proteins and mass spectrometry}

Coomassie Blue-stained bands (matching serotonylated bands on the overlay) were excised from the gel and cut into $1 \mathrm{~mm}^{3}$ cubes. In-gel trypsin digestion was performed as described previously (Mishra et al. 2007a,b). In brief, gel pieces were washed in $100 \mathrm{mM} \mathrm{NH}_{4} \mathrm{HCO}_{3}$ for $10 \mathrm{~min}$, centrifuged, and the supernatant was discarded. Next, they were washed in $40 \%$ acetonitrile (ACN) in $100 \mathrm{mM} \mathrm{NH}_{4} \mathrm{HCO}_{3}$ for $10 \mathrm{~min}$, and subsequently in ACN 5X gel volume for 5 min. These washing steps were repeated until all visible dye in the gel disappeared. The pieces were vacuum-dried briefly, then bathed in 3X gel volume of $10 \mathrm{mM}$ dithiothreitol in $100 \mathrm{mM} \mathrm{NH} \mathrm{HCO}_{3}$ for $45 \mathrm{~min}$ at $55^{\circ} \mathrm{C}$, centrifuged, and the liquid was discarded. The difference between the volume of the liquid added and discarded was the volume of trypsin used for in-gel digestion. Then, $5 \mathrm{ng} / \mu \mathrm{l}$ of trypsin in $50 \mathrm{mM} \mathrm{NH}_{4} \mathrm{HCO}_{3}$ containing $5 \mathrm{mM} \mathrm{CaCl}_{2}$ were added to the gel fragments and incubated at $37^{\circ} \mathrm{C}$ 
overnight. Peptides were extracted through liquid collection using $0.01 \%$ trifluoroacetic acid in $50 \%$ ACN and absolute CAN, and processed for mass spectrometry (Mishra et al. $2007 a, b$, Fofana et al. 2010).

\section{ATP/GTP-binding assays}

Cell culture and transfection were carried out as described above. At $48 \mathrm{~h}$ post-transfection, cells were rinsed in PBS and sensitized to glucose for $30 \mathrm{~min}$ in glucose-free standard medium. The cells were rinsed again in PBS and incubated in medium containing either 3.3 or $16.7 \mathrm{mM}$ glucose for 7 and $30 \mathrm{~min}$. After lysis, the supernatant was collected and $100 \mu \mathrm{g}$ of lysates (total protein) were incubated with $20 \mu \mathrm{l}$ of either GTP-agarose resin $(50 \%(\mathrm{v} / \mathrm{v})$ slurry in $10 \mathrm{mM}$ Tris $/ 300 \mathrm{mM}$ $\mathrm{NaCl} / 1 \mathrm{mM}$ EDTA, $\mathrm{pH} 8 \cdot 0$ ) or ATP-agarose resin diluted in kinase buffer (50 mM Tris- $\mathrm{HCl}, \mathrm{pH} 7 \cdot 5,10 \mathrm{mM} \mathrm{MgCl}$ ) to a total volume of $300 \mu \mathrm{l}$ for $2 \mathrm{~h}$ at $4{ }^{\circ} \mathrm{C}$. The resin was subjected to five cycles of washing and centrifugation using ice-cold TBST before the agarose beads were resuspended in $50 \mathrm{mM}$ Tris-HCl buffer $(\mathrm{pH} 7 \cdot 5)$. The pulled-down protein was analyzed by western blot utilizing an anti-Myc antibody to determine the quantity of Myc-TG2 bound to the ATP/GTP-agarose beads.

\section{MTT assay}

In living cells, yellow 3-(4,5-dimethylthiazol-2-yl)-2,5diphenyltetrazolium bromide (MTT) is reduced to purple formazan by mitochondrial reductases. INS-1E cells were cultured in 96 -well plates at $60 \%$ confluency and transfected, as applicable, with vectors expressing $M y c$-tagged TG2 WT and TG2 mutants and then further cultured for $48 \mathrm{~h}$. The culture media were replaced with media containing $0.5 \mathrm{mg} / \mathrm{ml}$ MTT, and the INS-1E cells were further incubated for $3 \mathrm{~h}$ at $37^{\circ} \mathrm{C}$. The media were then carefully removed and replaced with DMSO to dissolve formazan. The INS-1E cells were incubated with DMSO for $30 \mathrm{~min}$ in the dark at room temperature. The production of formazan was quantified by measuring absorbancy at 540 and $630 \mathrm{~nm}$ using a FLUOstar OPTIMA plate reader (BMG Labtechnologies $\mathrm{GmbH}$, Ortenberg, Germany) and was expressed as a percentage of the positive control (Lee et al. 2010).

\section{Reactive oxygen species assay}

Cellular reactive oxygen species (ROS) generation in INS-1E cells was determined using the fluorescent probe 5-(and-6)-chloromethyl-2', $7^{\prime}$-dichlorodihydrofluorescein diacetate (CM- $\mathrm{H}_{2}$ DCFDA) as described before (Lee et al. 2010). CM- ${ }_{2}$ DCFDA passes freely through cellular membranes and is deacetylated by intracellular esterases. This deacetylation results in the non-fluorescent compound 5-(and-6)-chloromethyl$2^{\prime}, 7^{\prime}$-dichlorodihydrofluorescein $\left(\mathrm{CM}-\mathrm{H}_{2} \mathrm{DCF}\right)$, which is rapidly oxidized into the highly fluorescent compound CM-DCF. The INS-1E cells were cultured in 96-well plates at $60 \%$ confluency, transfected with various TG2 constructs, and were incubated for $48 \mathrm{~h}$. The culture media were replaced with $16.7 \mathrm{mM}$ glucose/KRB buffer containing $5 \mu \mathrm{M}$ CM- $\mathrm{H}_{2}$ DCFDA and the cells were incubated at $37^{\circ} \mathrm{C}$ for $1 \mathrm{~h}$. KRB buffer was replaced with PBS after washing, to remove extracellular dye. Fluorescence intensity was measured at an excitation wavelength of $488 \mathrm{~nm}$ and an emission wavelength of $505 \mathrm{~nm}$ using the FLUOstar OPTIMA plate reader and was expressed as a percentage of the positive control.

\section{Statistical analysis}

Results are presented as means \pm s.e.m. One-way ANOVA with Dunnett's test was used for multiple comparisons. $P$ values $<0.05$ were considered significantly different.

\section{Results}

\section{Reduced insulin secretion from pancreatic islets isolated from TG2-null $\left(\mathrm{TG2}^{-/-}\right)$mice}

$T G 2^{-/-}$mice have impaired glucose tolerance as a result of reduced insulin secretion from the pancreatic islets (Bernassola et al. 2002). To confirm that the reduced insulin secretion in $T G 2^{-/-}$mice is a result of the loss of TG2 function in the pancreatic islets and not due to other peripheral factors, we measured GSIS from the pancreatic islets isolated from the WT and $T G 2^{-/-}$mice. No difference in insulin secretion was observed between the pancreatic islets from the WTand $T G 2^{-/-}$mice under basal glucose $(3 \cdot 3 \mathrm{mM})$ levels (Fig. 1A). However, in response to glucose stimulation $(16 \cdot 7 \mathrm{mM})$, a significant $(P<0 \cdot 01)$ reduction in insulin secretion from the pancreatic islets of $T G 2^{-/-}$mice was observed in comparison with WT mice (Fig. 1A). These results confirm that the lack of $T G 2$ reduces GSIS from the pancreatic islets.

\section{Reduced insulin secretion from INS-1E cells overexpressing Myc-TG2 mutants}

Reduced insulin secretion from the pancreatic islets of $\mathrm{TG}^{-/-}$mice confirms the importance of WT-TG2 for $\beta$-cell function (Bernassola et al. 2002). To further establish the role of TG2 in $\beta$-cell function, we sought to demonstrate whether naturally occurring mutations also affect TG2 activity and its function on $\beta$-cell function. INS-1E cells were transfected with WT 
A

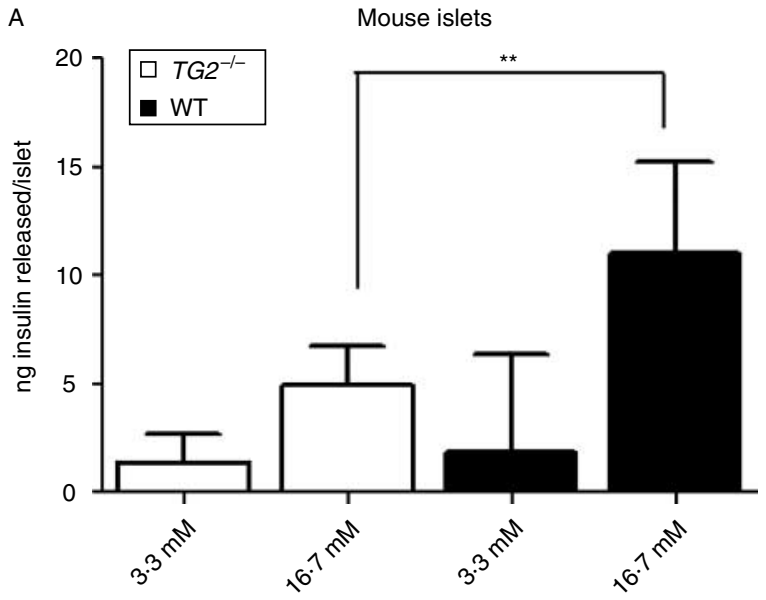

B

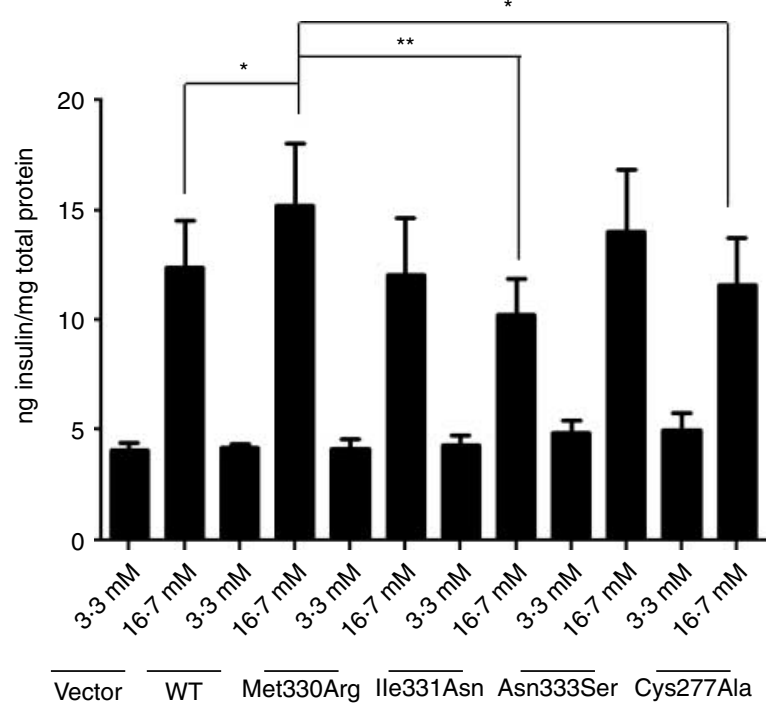

Figure 1 Glucose-stimulated insulin secretion from the pancreatic islets and INS-1E cells. (A) Batches of four islets were preincubated in KRB buffer containing $3.3 \mathrm{mM}$ glucose for $30 \mathrm{~min}$. The pre-incubation buffer was collected and the islets were subsequently incubated for $30 \mathrm{~min}$ in KRB buffer containing $16.7 \mathrm{mM}$ glucose. At the end of the incubation, the buffer was collected and insulin was measured by a mouse insulin ELISA kit (mean \pm S.E.M., $n=12 ;{ }^{\star \star} P<0 \cdot 01$ ). (B) INS-1E cells were cultured in $60 \mathrm{~mm}$ tissue culture plates at $60 \%$ confluency and then transfected with various TG2 constructs. After $48 \mathrm{~h}$, the cells were rinsed in PBS, sensitized to glucose in glucose-free KRB buffer and, finally, incubated in KRB buffer containing either 3.3 or $16.7 \mathrm{mM}$ glucose for $30 \mathrm{~min}$. The buffer was then collected and analyzed for insulin concentration using a rat insulin ELISA kit as described in the Materials and methods section. Insulin concentration was normalized to the total cellular protein content.

(Mean \pm S.E.M., $n=5 ;{ }^{\star}<0 \cdot 05 ;{ }^{\star \star} P<0 \cdot 01$ ). V, vector;

WT, wild-type; 277, 330, 331 and 333 represent TG2 mutants. and naturally occurring mutant-TG2 constructs. Post-transfection, INS-1E cells were batch-challenged with glucose and insulin secretion was measured in the conditioned media. A significant increase in GSIS was found in cells transfected with WT in comparison with the vector-only control group (Fig. 1B). However, GSIS was consistently found to be lower in INS-1E cells transfected with TG2 mutants in comparison with cells transfected with WT-TG2 (Fig. 1B). This indicates that TG2 function(s) involved in insulin secretion is impaired in the naturally occurring $T G 2$ mutants. The maximum reduction was found in Ile331Asn-TG2 (32\%) followed by Met330Arg-TG2 (20\%) and the least (7\%) in Asn333Ser-TG2 (Fig. 1B). A reduction in GSIS $(22.75 \%)$ was also found in INS-1E cells transfected with the Cys277Ala-TG2 mutant lacking transamidation function, suggesting a role for the transamidation function of TG2 in GSIS (Fig. 1B). Similar results were found with RINm5F $\beta$-cells (data not shown).

To study the effect of TG2 mutants on insulin secretory phases, insulin secretion was determined during the perifusion of INS-1E spheroidal clusters (Merglen et al. 2004). Both the first and second phases of GSIS were upregulated in spheroids overexpressing WT-TG2 in comparison with vector-transfected spheroids (Fig. 2). Both GSIS phases were reduced in spheroids expressing Ile331Asn-TG2 and the transamidation-null Cys277Ala-TG2 in comparison with WT-TG2 (Fig. 2). However, Cys277Ala-TG2-expressing INS-1E cells secreted more insulin in comparison with the vector-only control group (Fig. 2). Together, these data suggest that TG2 contributes to both phases of insulin secretion.

\section{Cellular localization and expression of TG2 mutants}

To verify that the cellular localization, expression and stability of TG2 mutants are not altered and are similar to WT-TG2, INS-1E cells were transfected with various TG2 constructs and processed for fluorescence microscopy and immunoblotting. Intracellular localization and expression levels of TG2 mutants were found to be similar to WT-TG2, suggesting that naturally occurring mutations in $T G 2$ have no effect on cellular localization, stability and expression of TG2 (Fig. 3).

\section{TG2 mutants have no effect on the viability of INS-1E cells}

TG2 has been associated with cell viability and cell death (Fesus \& Piacentini 2002). To determine whether reduced insulin secretion from INS-1E cells overexpressing TG2 mutants was due to reduced cell viability, we performed the MTT assay. No difference in cell viability 


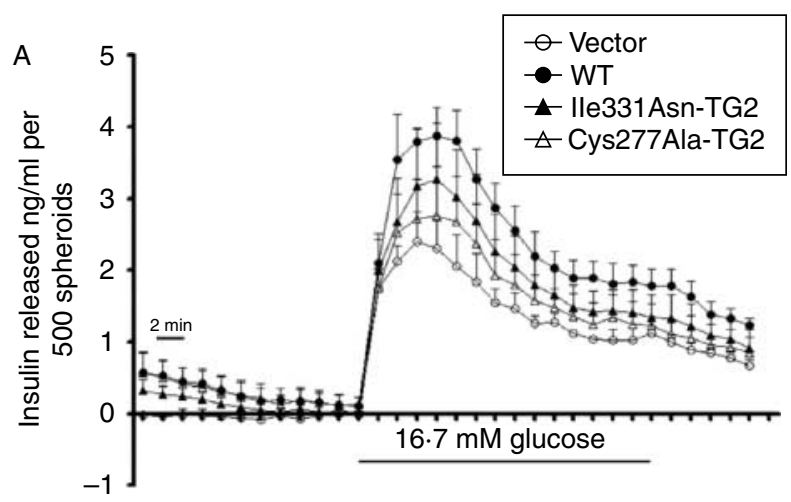

B
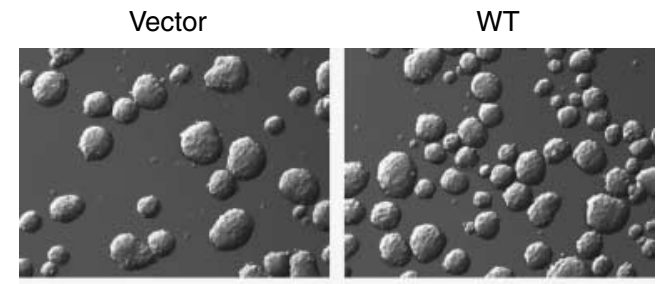

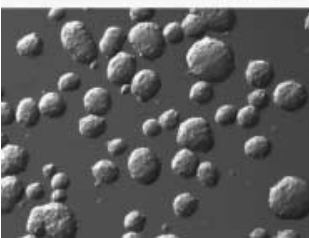

Ile331Asn

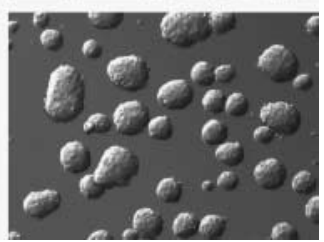

Cys277Ala
Figure 2 Effect of WT and mutant TG2 overexpression on GSIS from spheroidal clusters composed of INS-1E cells.

(A) INS-1E spheroids expressing WT and mutant TG2 were perifused at $0.3 \mathrm{ml} / \mathrm{min}$ with basal $3.3 \mathrm{mM}$ glucose prior to stimulation with $16.7 \mathrm{mM}$ glucose. Data points show insulin released expressed as mean \pm S.E.M. $\mathrm{ng} / \mathrm{ml}$ per 500 spheroids $(n=3)$. (B) Representative photomicrographs of spheroidal clusters of INS-1E cells used for the perifusion experiments.

was observed among the different groups, except that Ile331Asn-TG2-overexpressing cells had a non-significant reduction in cell viability in comparison with the vector and WT TG2-transfected control groups (Fig. 4A).

\section{Reduced ROS levels in INS-1E cells overexpressing Myc-TG2 mutants}

In addition to the detrimental effect of ROS on $\beta$-cell function, emerging evidence suggests that ROS signaling plays a role in GSIS (Szypowska \& Burgering 2011). To investigate whether the overexpression of TG2 mutants alters intracellular ROS production, we measured ROS levels in INS-1E cells transfected with various TG2 mutants. A decrease in ROS level was observed in INS-1E cells overexpressing TG2 mutants, including the transamidation-null Cys277Ala-TG2 (Fig. 4B). These results are consistent with an earlier report showing decreased ROS production in cancer cells as a result of the downregulation of TG2 (Bae et al. 2006).

\section{TG2 mutants have altered enzymatic activities}

To determine which function of TG2 is affected in the naturally occurring TG2 mutants, INS-1E cells were transfected with WT and mutant Myc-TG2 constructs. Subsequently, Myc-TG2 was affinity purified using a Myc-IP kit and used for the measurement of TG2 transamidation and kinase activities by in vitro assays. A reduction in both transamidation and kinase activities was found in TG2 mutants in comparison with the WT control (Fig. 5). A maximum reduction in

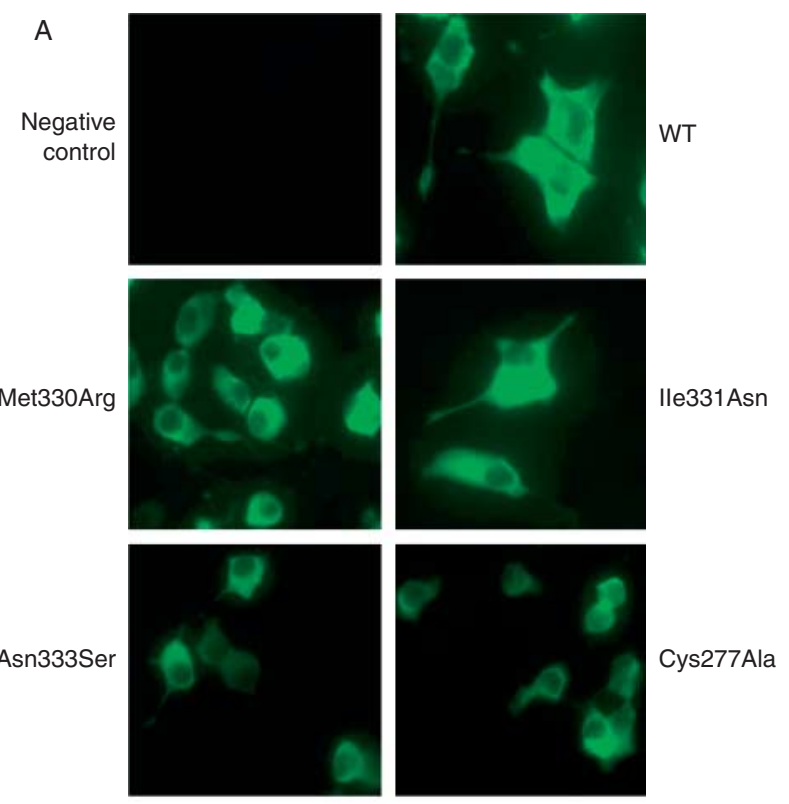

B

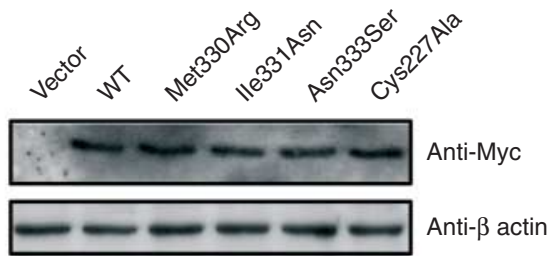

Figure 3 Expression patterns of TG2 and TG2 mutants in INS-1E cells. INS-1E cells were transfected with various Myc-TG2 constructs at $60 \%$ confluency. At $48 \mathrm{~h}$ post-transfection, the cells were processed for fluorescence microscopy and immunoblotting. (A) For fluorescence microscopy, the cells grown in chambered slides were first incubated with a rabbit anti-Myc primary antibody (1:200 in 1\% BSA) and then with an Alexa Fluor 488-conjugated anti-rabbit secondary antibody (1:300 in 1\% BSA). After mounting, the cells were visualized by fluorescence microscopy. WT-TG2transfected cells without primary antibody exposure were used as a negative control. (B) For immunoblot analysis, the cells were grown in $60 \mathrm{~mm}$ culture discs. Equal amounts of proteins $(30 \mu \mathrm{g})$ were separated by SDS-PAGE and transferred onto nitrocellulose membranes. The membranes were sequentially incubated with a rabbit anti-Myc primary antibody $(1: 1000)$ and then with a HRP-conjugated secondary antibody (1:3000) as described in the Materials and methods section, and visualized by enhanced chemiluminescence. Empty vector-transfected cells were included as a negative control and $\beta$-actin blot as a loading control. 

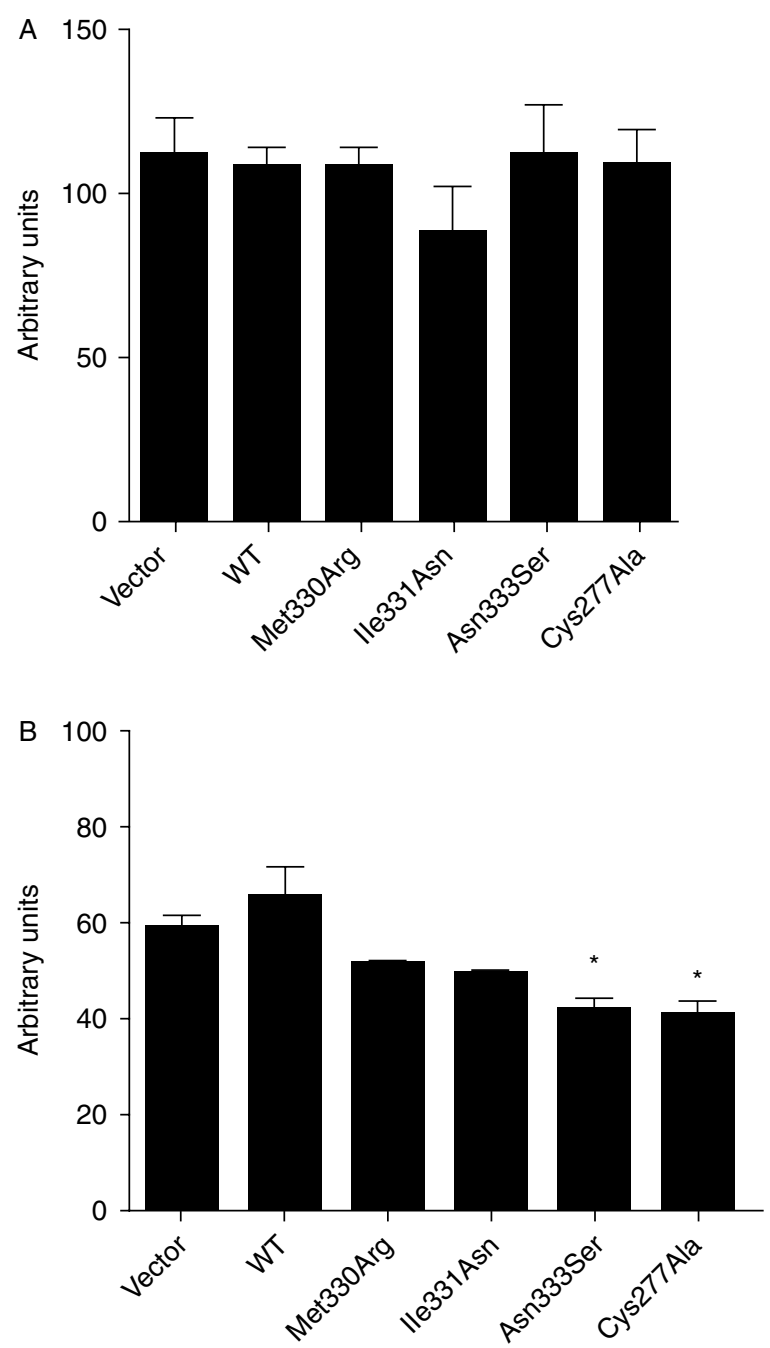

Figure 4 Effect of WT and mutant TG2 overexpression on cell viability and ROS generation in INS-1E cells. INS-1E cells were transfected with WT and mutant TG2. Cell viability was determined by the MTT assay $(A)$ and ROS levels were measured using the fluorescent probe 5-(and-6)-chloromethyl-2', $7^{\prime}$-dichlorodihydrofluorescein diacetate (CM- $\mathrm{H}_{2}$ DCFDA) (B) as described in the Materials and methods section. One-way ANOVA $(n=4) .{ }^{*} P<0.05$.

TG2 transamidation activity was observed in Asn333SerTG2 $(P<0 \cdot 01)$ followed by Ile331Asn-TG2 $(P<0 \cdot 05)$ and the least in Met330Arg-TG2 (Fig. 5A). In addition, we examined the in situ transamidation activity of $T G 2$ mutants in INS-E1 cells using biotinylated $\mathrm{BPNH}_{2}$ as an amine substrate. A similar pattern of transamidation activity in TG2 mutants was found as that of the in vitro transamidation assay, especially in the lower half of the blots where the transamidated protein bands were relatively distinct from each other (Fig. 5B). In the case of kinase activity, a reduction in the range of $15-23 \%$ was found in all TG2 mutants including transamidation activity-dead mutant-TG2 (Fig. 5C). However, no difference in kinase activity was observed when the assay was performed at the 7-min time point in response to glucose stimulation (Fig. 5C). Collectively, these data suggest that the naturally occurring TG2 mutants have impaired transamidation and kinase activities. However, the effect on transamidation activity was found to be more pronounced than the effect on kinase activity.

\section{Naturally occurring mutations in TG2 differentially affect GTP-binding function}

To determine the effect of the naturally occurring TG2 mutations on its GTP-binding function, cell lysates prepared from INS-1E cells transfected with various Myc-TG2 constructs were processed for the pull-down assay using GTP-agarose affinity resin. GTP-agarose resin comprises GTP attached to the agarose beads via its $\gamma$-phosphate and is resistant to phosphatases present in crude cell/tissue extracts (Iismaa et al. 1997). GTP resin-bound TG2 was analyzed by immunoblotting using an anti-Myc antibody followed by densitometric analysis. Under the basal glucose concentration $(3.3 \mathrm{mM})$, WT-TG2 was found to have a low GTPbinding ability, whereas Ile331Asn-TG2 was unable to bind GTP and Met330Arg had a very weak GTP-binding ability (Fig. 6A and B). Surprisingly, Asn333Ser-TG2 was found to have elevated GTP-binding ability (Fig. 6A and B). Most importantly, the GTP-binding ability of WT- and Met330Arg-TG2 was found to be increased and that of Asn333Ser-TG2 was decreased in response to glucose stimulation (Fig. 6A and B). GTP binding to Ile331Asn-TG2 was found to be low under both conditions (Fig. 6A and B). A similar binding pattern was found with ATP for Ile331Asn- and Asn333Ser-TG2 (Fig. 6A and B). However, unlike GTP binding, WT- and Met330Arg-TG2 were found to have maximum ATP-binding ability (Fig. 6A and B). Furthermore, no apparent change in ATP binding was observed under the basal and high glucose concentrations (Fig. 6A and B). Similar to kinase activity, no difference in the GTP-binding ability of TG2 was observed in response to glucose stimulation when the assay was performed at the 7-min time point (Fig. 6C). Thus, the GTP-binding function was found to be increased in WT-TG2 by glucose stimulation only at the 30 -min time point and its loss more closely correlated with significantly reduced insulin secretion from INS-1E cells expressing Ile331Asn-TG2. Taken together, these data suggest an important role for the GTP-binding function of TG2 in GSIS from the pancreatic $\beta$-cells, which is most likely involved during the second phase of insulin secretion.

\section{Protein serotonylation in INS-1E cells overexpressing WT- and mutant-TG2}

Recently, activation of small GTPases through serotonylation by TG2 in response to glucose has been 
B In situ transamidation assay

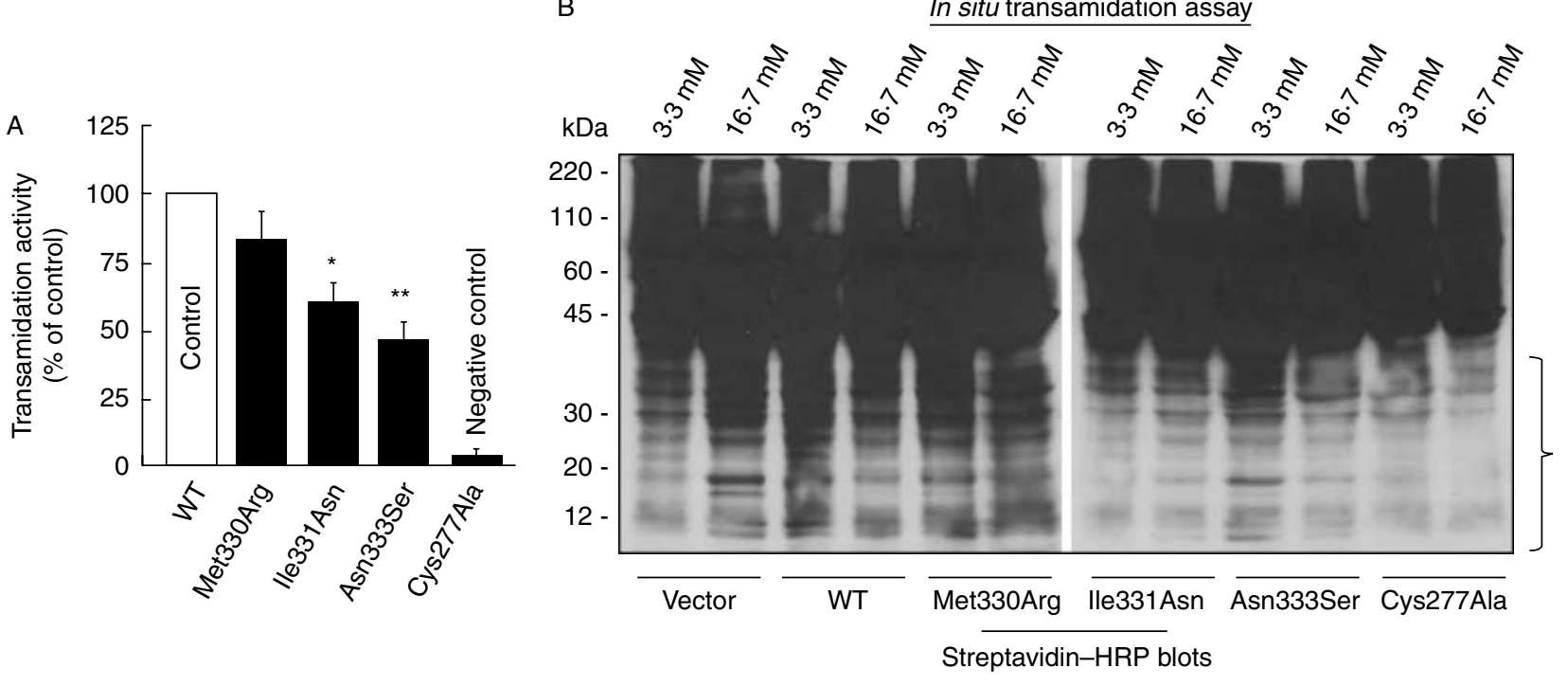

C
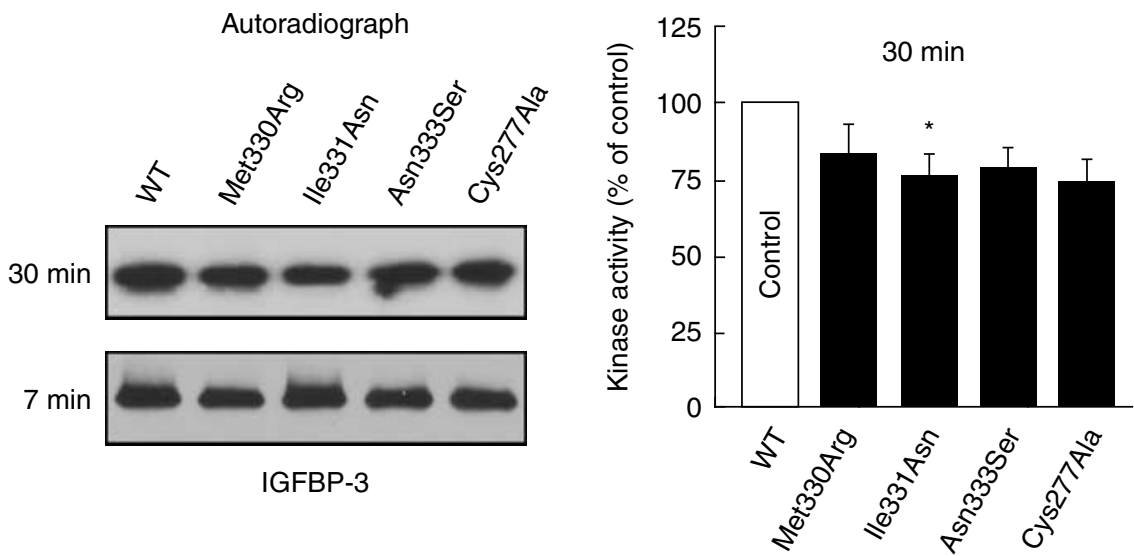

Figure 5 Impact of the naturally occurring mutations in TG2 on its enzymatic activities. Myc-tagged WT and mutant TG2 were affinity purified as described in the Materials and methods section. (A) Histogram showing the relative transamidation activity of WT and mutant TG2 as determined by in vitro transamidation (mean \pm s.E.M., $n=6$ ). ${ }^{*} P<0.05 ;{ }^{*} P<0.01$ vs WT control. (B) Western blot showing in situ transamidation activity using 5-(biotinamido)pentylamine $\left(\mathrm{BPNH}_{2}\right)$ as a substrate. Cell culture and transfection were performed as described in Fig. 1. Subsequently, INS-1E cells were pre-incubated for $1 \mathrm{~h}$ with $1 \mathrm{mM} \mathrm{BPNH}_{2}$ in standard culture medium. The cells were rinsed with PBS, and sensitized to glucose for $30 \mathrm{~min}$ in glucose-free standard medium and subsequently incubated in medium containing either 3.3 or $16.7 \mathrm{mM}$ glucose for $30 \mathrm{~min}$. The cells were then harvested and $30 \mu \mathrm{g}$ of proteins were analyzed by SDS-PAGE and western blot using streptavidin-HRP conjugate and ECL. (C) Autoradiographs showing the kinase activity of WT and mutant TG2 at the 7- and 30 -min time points in response to glucose stimulation as determined by an in vitro kinase assay. The in vitro kinase assay was performed in kinase buffer (50 mM Tris- $\mathrm{HCl}, \mathrm{pH} 7 \cdot 5,10 \mathrm{mM}$ magnesium chloride, $\left[\gamma^{-}{ }^{32} \mathrm{P}\right] \mathrm{ATP}(25 \mu \mathrm{Ci} / \mathrm{ml})$ ) containing IGFBP3 (2 $\left.\mu \mathrm{g}\right)$ in a final volume of $25 \mu \mathrm{l}$ at $30^{\circ} \mathrm{C}$. Subsequently, the mixture was resolved on SDS-PAGE and processed for autoradiography. Representative autoradiograph of three different experiments is shown. Histograms show relative changes in kinase activity as determined by the densitometric analysis of phosphorylated IGFBP3 (mean \pm S.E.M., $n=3$ ). ${ }^{*} P<0.05$.

reported to play a role in the regulation of insulin secretion from pancreatic $\beta$-cells (Paulmann et al. 2009). Our findings of reduced transamidation activity in TG2 mutants prompted us to examine protein serotonylation in INS-1E cells expressing various TG2 constructs. The overexpression of WT-TG2 was found to be sufficient to upregulate protein serotonylation in $\beta$-cells even under the basal glucose concentration in comparison with the vector-only control group (Fig. 7A). On the other hand, the overexpression of Cys277Ala-TG2 resulted in the downregulation of protein serotonylation (Fig. 7A). A significant upregulation of protein serotonylation was observed in cells expressing Asn333Ser-TG2 at the basal glucose concentration (Fig. 7A). Interestingly, out of the three major serotonylated bands, two were 
A
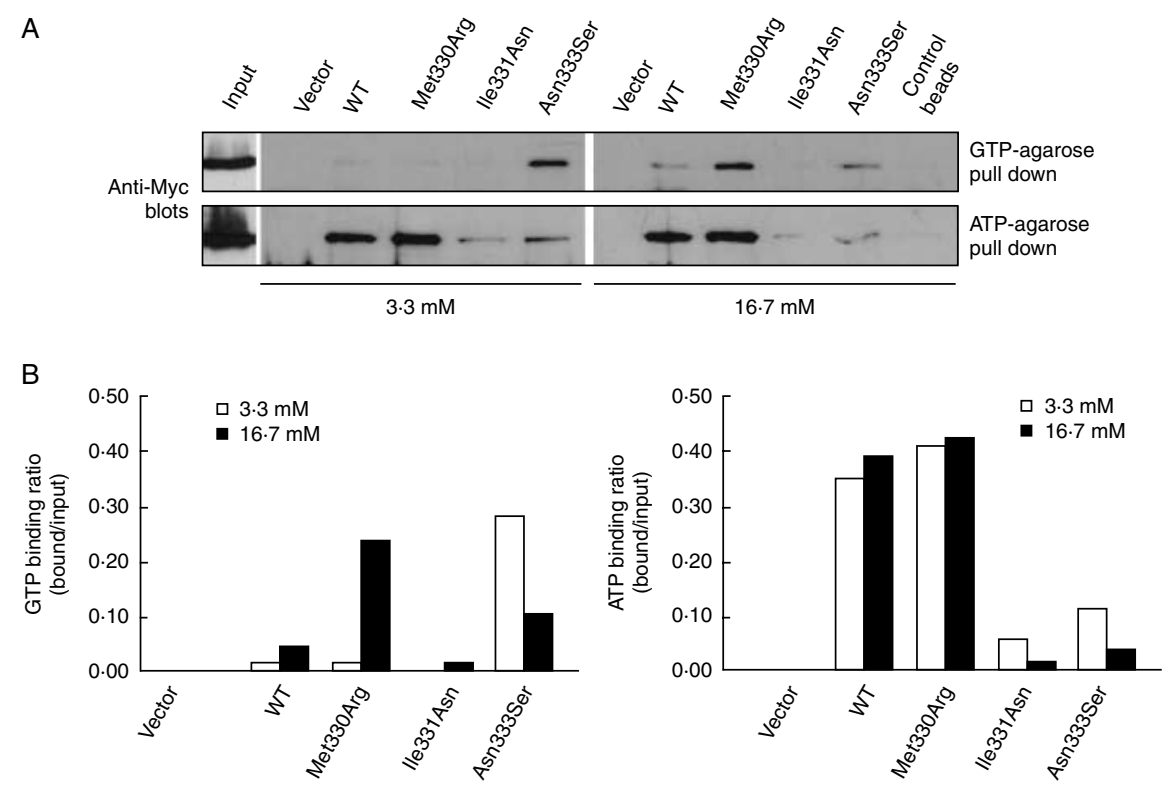

C

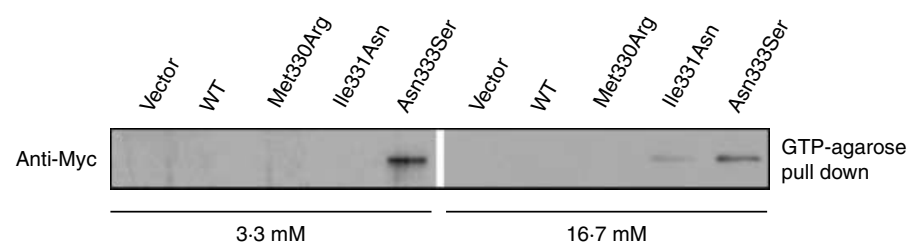

Figure 6 Impact of the naturally occurring mutations in TG2 on its GTP/ATP binding function. (A) INS-1E cells were transfected with various Myc-TG2 constructs. At $48 \mathrm{~h}$ post-transfection, the cells were incubated with basal $(3.3 \mathrm{mM})$ and high $(16.7 \mathrm{mM})$ glucose concentrations for $30 \mathrm{~min}$. Equal amounts of total proteins $(100 \mu \mathrm{g})$ of each sample were incubated with $20 \mu \mathrm{l} \mathrm{GTP}$ or ATP-agarose in $10 \mathrm{mM}$ Tris buffer $\left(\mathrm{pH} \mathrm{7.5)}\right.$ for $2 \mathrm{~h}$ at $4{ }^{\circ} \mathrm{C}$ on a rotating device. After washing, $30 \mu \mathrm{l}$ of loading buffer was added to each tube, boiled in a water bath for $10 \mathrm{~min}$ and analyzed by SDS-PAGE and immunoblotting using an anti-Myc antibody as described in Fig. 2.

(B) Histograms showing relative changes in GTP and ATP binding in WT and mutant TG2 as shown in (A). (C) Anti-Myc immunoblots showing GTP-binding ability of WT and mutant TG2 in response to glucose stimulation (for $7 \mathrm{~min}$ ). The experiment was performed as described in $(A)$.

downregulated in response to glucose stimulation, whereas one remained unchanged in cells expressing Asn333Ser-TG2 (Fig. 7A). In contrast, all three bands were consistently upregulated in cells overexpressing WT and Met330Arg-TG2 under the high glucose concentration. Furthermore, a unique serotonylated band appeared in response to glucose stimulation in cells expressing Ile331Asn-TG2, most likely due to proteolytic cleavage of the $72 \mathrm{kDa}$ band (Fig. 7A). Subsequently, we analyzed protein serotonylation in the pancreatic islets from the WT and $T G 2^{-/-}$mice in response to glucose stimulation. A similar band pattern of serotonylated proteins was found in both cases as in INS-1E cells; however, a difference in protein serotonylation was apparent between the WT and $T G 2^{-/-}$mice (Fig. 7B). Unexpectedly, out of the three prominently serotonylated bands, two were upregulated in the pancreatic islets from the $T G 2^{-/-}$mice, whereas a decrease in serotonylation was found in the $72 \mathrm{kDa}$ band (Fig. 7B). This may be a result of a compensatory response through an upregulation of other members of the TG family of proteins (Porzio et al. 2007). However, the inability to compensate the serotonylation of the $72 \mathrm{kDa}$ band may be associated with reduced insulin secretion in $T G 2^{-/-}$mice, which is consistent with the data obtained in INS-1E cells expressing the naturally occurring TG2 mutants, especially Ile331Asn-TG2. To reveal the identity of this uniquely serotonylated $72 \mathrm{kDa}$ protein band, the band was excised from an identical Coomassie Blue-stained gel and processed for mass spectrometry. A number of GTP-binding proteins were identified (Table 2). These data are consistent with a recent report on an important role of serotonylation of GTPases in insulin secretion from $\beta$-cells. 


\section{A}
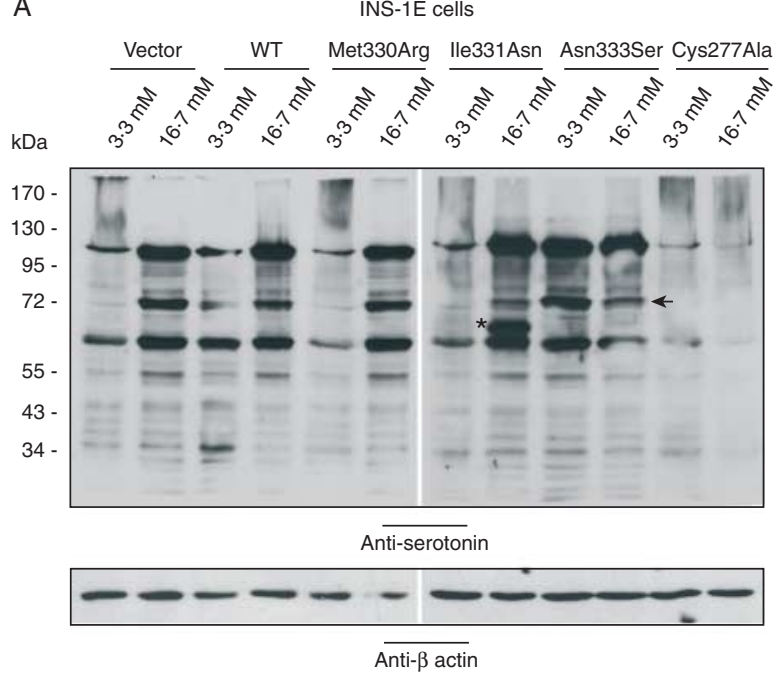

B

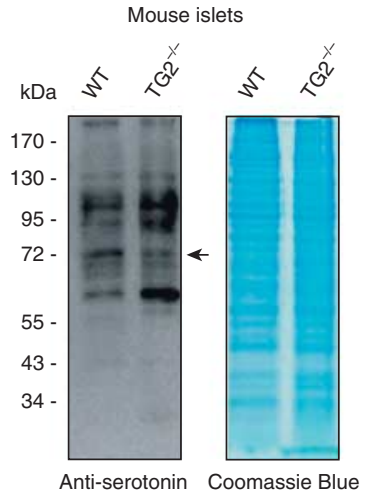

Figure 7 Protein serotonylation in INS-1E cells overexpressing TG2 and TG2 mutants. (A) Cell culture, transfection and treatment were performed as described in Figs 1,2 and 3. Subsequently, the cells were harvested and equal amounts of proteins were analyzed by SDS-PAGE and immunoblotting using an antiserotonin antibody (1:500). $\beta$-Actin immunoblots are shown as a loading control. The $72 \mathrm{kDa}$ serotonylated protein is shown with an arrow $(\leftarrow)$ and a unique serotonylated band in the case of Ile331Asn-TG2 is indicated by an asterisk (*). (B) Anti-serotonin immunoblot showing protein serotonylation in the pancreatic islets in response to glucose stimulation from the WT and TG2-null $\left(T G 2^{-1-}\right)$ mice. Coomassie Blue-stained gel is shown as a loading control.

\section{Discussion}

In this study, we analyzed the effect of naturally occurring mutations in TG2 on its transamidation, kinase, and GTP-binding functions and their association with GSIS. Our results indicate that all three reported mutations in TG2 differentially affect TG2 biological functions. This is consistent with the location of these mutations in close proximity of the transamidation catalytic triad $\left(\mathrm{Cys}^{277}, \mathrm{His}^{335}\right.$, and $\mathrm{Asp}^{358}$ ) and in the proximity of the residues involved in GTP/ATP binding (Fig. 8). In fact, the $\mathrm{Met}^{330}$, Ile ${ }^{331}$, and $\mathrm{Asn}^{333}$ mutation sites in TG2 are sandwiched between the transamidation catalytic triad and GTP/ATP binding residues in TG2 (Fig. 8).

TG2 activity is regulated by ATP, GTP, and $\mathrm{Ca}^{2+}$. Protein transamidation by TG2 is inhibited by both ATP and GTP and activated by $\mathrm{Ca}^{2+}$, whereas TG2 kinase activity is inhibited by $\mathrm{Ca}^{2+}$ and promoted by ATP (Mishra \& Murphy 2004, Mishra et al. $2007 a, b$ ). As ATP and $\mathrm{Ca}^{2+}$ modulate both TG2 transamidation and kinase activities and GSIS requires the upregulation of ATP and $\mathrm{Ca}^{2+}$ in a sequential manner within $\beta$-cells (Yada 1994, Pinkas et al. 2007), both TG2 activities may potentially contribute to insulin secretion. A reduction in the transamidation activity of TG2 mutants and a consistent decrease in insulin secretion from INS-1E cells overexpressing these mutants suggest a role for transamidation activity in insulin secretion. These results are in line with earlier reports on the reduction of insulin secretion from rat $\beta$-cells treated with inhibitors of TG2 transamidation activity (Bungay et al. 1986, Driscoll et al. 1997). However, the increase in $\mathrm{Ca}^{2+}$ level that leads to insulin secretion in $\beta$-cells in response to glucose is much lower $(\sim 150-250 \mathrm{nM})$ than the level of $\mathrm{Ca}^{2+}(\sim 150-500 \mu \mathrm{M})$ required for TG2 transamidation activity (Lai et al. 1997, Parkash et al. 2002). In addition, intracellular levels of GTP, which is known to inhibit transamidation activity, are many fold higher $(\sim 100 \mu \mathrm{M})$ than $\mathrm{Ca}^{2+}$ levels (Siegel \& Khosla 2007). It is possible that ATP/GTP binding or other changes in TG2 (e.g. phosphorylation) alter the $\mathrm{Ca}^{2+}$ sensitivity of TG2, resulting in the activation of the transamidation function. However, the relatively lower reduction in insulin secretion from cells overexpressing the transamidation activity-dead Cys277Ala-TG2 mutant and the Asn333Ser-TG2 natural mutant with the greatest loss of transamidation activity, compared with cells overexpressing the Ile331Asn-TG2 mutant, suggests that TG2 transamidation activity per se is not sufficient in this process.

We then analyzed serotonylated proteins as a specific instance of transamidation, and we found that an approximately $72 \mathrm{kDa}$ serotonylated protein band was more dynamically altered especially in the pancreatic islets from the $T G 2^{-/-}$mice and in INS-1E cells expressing the Ile331Asn-TG2 natural mutant, which have the greatest reduction in insulin secretion. This suggests that the $72 \mathrm{kDa}$ protein band may be an important target for serotonylation (transamidation) associated with insulin secretion. Analysis of the $\sim 72 \mathrm{kDa}$ serotonylated band by mass spectrometry identified a number of Rab GTPases. It should be noted that the molecular masses of proteins identified by mass spectrometry are lower than the molecular mass of the overlay serotonylated band excised from the Coomassie Blue-stained reducing gel. This would mean that these 
Table 2 List of proteins identified by mass spectrometry in the $72 \mathrm{kDa}$ serotonylated band

\begin{tabular}{|c|c|c|c|c|}
\hline $\begin{array}{l}\text { Uniprot/SWISSPROT or } \\
\text { Ref Seq_peptide no. }\end{array}$ & $\begin{array}{l}\text { Probability } \\
\log (e) \text { score }^{a}\end{array}$ & $\begin{array}{c}\text { No. of } \\
\text { unique } \\
\text { peptides }\end{array}$ & Mr & Protein \\
\hline P48036 & $-168 \cdot 2$ & 18 & $35 \cdot 6$ & ANXA5, annexin-A5 \\
\hline P55260 & $-115 \cdot 1$ & 11 & $35 \cdot 7$ & $\begin{array}{l}\text { ANXA4, annexin-A4 (36 kDa zymogen granule } \\
\text { membrane-associated protein) }\end{array}$ \\
\hline Q9Z2L0 & $-113 \cdot 3$ & 12 & $32 \cdot 2$ & VDAC1, voltage-dependent anion channel 1 \\
\hline P63245 & -80 & 9 & $35 \cdot 4$ & GNB2/1, guanine nucleotide-binding protein subunit beta-2-like 1 \\
\hline Q09073 & $-54 \cdot 7$ & 8 & $32 \cdot 9$ & SLC25A5, ADP/ATP translocase 2 (solute carrier family 25 ) \\
\hline P81115 & $-53 \cdot 3$ & 7 & $31 \cdot 8$ & VDAC2, voltage-dependent anion channel 2 \\
\hline Q6NYB7 & $-45 \cdot 5$ & 7 & $22 \cdot 4$ & RAB1, Ras-related protein Rab-1A \\
\hline Q05962 & $-44 \cdot 4$ & 3 & $32 \cdot 9$ & SLC25A4, ADP/ATP translocase 1 (solute carrier family 25) \\
\hline Q9R1Z0 & $-41 \cdot 4$ & 4 & $30 \cdot 9$ & VDAC3, voltage-dependent anion channel 3 \\
\hline Q9Z269 & $-40 \cdot 3$ & 5 & $26 \cdot 9$ & $\begin{array}{l}\text { VAMP-associated protein B, Vesicle-associated membrane } \\
\text { protein-associated protein B }\end{array}$ \\
\hline P09527 & $-37 \cdot 9$ & 4 & $23 \cdot 5$ & RAB7A, Ras-related protein Rab-7a \\
\hline P53994 & $-29 \cdot 3$ & 4 & $23 \cdot 5$ & RAB2A, Ras-related protein Rab-2A \\
\hline NP_596909 & $-26 \cdot 6$ & 4 & $31 \cdot 4$ & SLC25A10 (solute carrier family 25 ) \\
\hline P10536 & -22 & 1 & $22 \cdot 2$ & RAB1B, Ras-related protein Rab-1B \\
\hline Q9Z270 & -21 & 2 & $27 \cdot 8$ & $\begin{array}{l}\text { VAMP-associated protein A, Vesicle-associated membrane } \\
\text { protein-associated protein A }\end{array}$ \\
\hline NP_001099310 & $-14 \cdot 3$ & 2 & $25 \cdot 2$ & RAB5C, Ras-related protein Rab-5C \\
\hline P61107 & -13.5 & 2 & $23 \cdot 9$ & RAB14, Ras-related protein Rab-14 \\
\hline Q4KM74 & $-11 \cdot 8$ & 2 & $24 \cdot 7$ & Vesicle-trafficking protein SEC22b \\
\hline P97700 & -11 & 2 & $34 \cdot 1$ & SLC25A11 (solute carrier family 25 member 11 ) \\
\hline 035509 & -9.5 & 2 & $24 \cdot 5$ & RAB11B, Ras-related protein Rab-11B \\
\hline NP_001100389 & $-6 \cdot 7$ & 2 & $34 \cdot 4$ & Actin-related protein $2 / 3$ \\
\hline NP_00103405 & $-5 \cdot 1$ & 1 & $23 \cdot 7$ & RAB5B, Ras-related protein Rab-5B \\
\hline XP_343460 & $-3 \cdot 2$ & 1 & $23 \cdot 4$ & RAB6B, Ras-related protein Rab-6B \\
\hline P16036 & -1.9 & 1 & 39.6 & $\begin{array}{l}\text { Phosphate carrier protein } \\
\text { (solute carrier family } 25 \text { member } 3 \text { ) }\end{array}$ \\
\hline P62747 & $-1 \cdot 7$ & 1 & $22 \cdot 1$ & Rho-related GTP-binding protein RhoB \\
\hline Q62636 & $-1 \cdot 6$ & 1 & 20.8 & GTP-binding protein smg p21B \\
\hline P63012 & -1.5 & 1 & 25 & RAB3A, Ras-related protein Rab-3A \\
\hline NP_001100085 & $-1 \cdot 3$ & 1 & $19 \cdot 5$ & Actin-related protein $2 / 3$ complex, subunit 4 , subunit 4 \\
\hline
\end{tabular}

${ }^{\mathrm{a} B a s e}-10 \log$ of expectation that this assignment is stochastic. Low expect score $(<-3 \cdot 0)$ corresponds to a confident identification. Bold - proteins with a $\log$ expect score $>-3$.

proteins are not only serotonylated, but also crosslinked. A unique serotonylated band that appeared only in the case of Ile331Asn-TG2 in response to glucose stimulation may be due to the perturbed crosslinking of serotonylated proteins rather than the cleavage of the $72 \mathrm{kDa}$ serotonylated band. As observed for transamidation, there was no correlation between insulin secretion and serotonylation levels of the $\sim 72 \mathrm{kDa}$ band in the vector and Cys277Ala-TG2 control groups, suggesting that protein serotonylation per se is not sufficient to explain the insulin secretory phenotype of INS-1E cells overexpressing TG2 mutants. In addition to Rab GTPases, a number of actin, tubulin, and vesicle membrane network proteins were also identified by mass spectrometry in the $72 \mathrm{kDa}$ serotonylated protein band. As Rab GTPases regulate many steps of membrane traffic, including vesicle formation, vesicle movement along with actin and tubulin networks, and membrane fusion, it is possible that serotonylation of these cytoskeletal and vesicle membrane network proteins is involved in GSIS from $\beta$-cells.
Moreover, our results suggest that naturally occurring mutations in TG2 differentially affect GTP- and ATPbinding function of TG2. Most importantly, GTPbinding ability was found to be increased in WT-TG2 in response to glucose stimulation only at $30 \mathrm{~min}$ (i.e. corresponding to the second phase of insulin secretion) and its loss was more closely correlated in the Ile331Asn-TG2 mutant with the greatest reduction in insulin secretion. A lack of the correlation between GTP/ATP-binding ability and the reduction in insulin secretion in the case of the Asn333Ser-TG2 mutant may be due to the compensatory effect of ATP on GTP binding, which is not the case with the Ile331Asn-TG2 mutant. However, a lack of the correlation between GTP/ATP binding and decreased insulin secretion in Met330Arg-TG2 again suggests the involvement of more than one function of TG2 in insulin secretion. Furthermore, our findings of the impaired GTPbinding function of naturally occurring TG2 mutants are consistent with an earlier report by Murthy et al. (2002) in which the substitution of a conserved 


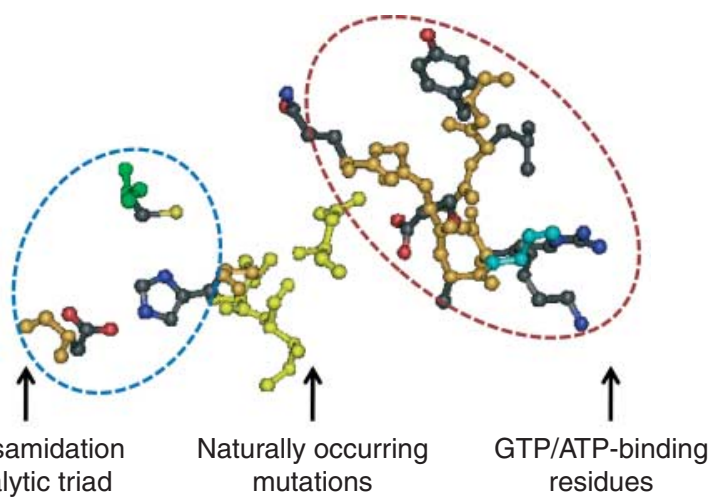
catalytic triad

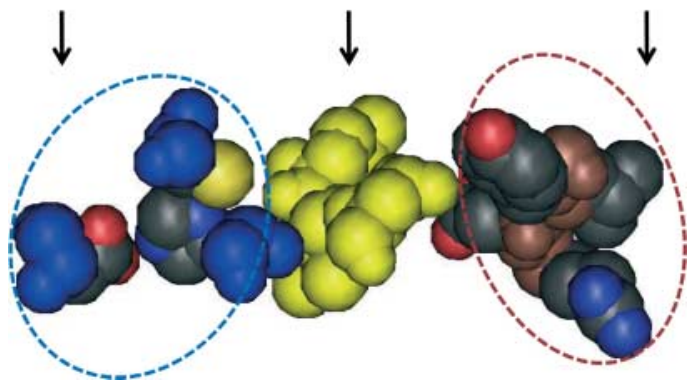

Figure 8 Naturally occurring mutations in TG2 are flanked between the transamidation catalytic triad and GTP-binding residues. Relative position of the transamidation catalytic triad $\left(\mathrm{Cys}^{277}\right.$, $\mathrm{His}^{335}$, and $\left.\mathrm{Asp}^{358}\right)$, naturally occurring mutations (Met $^{330}, \mathrm{Ile}^{331}$, and Asn ${ }^{333}$ ), and GTP/ATP-binding loops $\left({ }^{169} \mathrm{Gln}\right.$-Gly-Ser-Ala-Lys ${ }^{173}$ and ${ }^{580}$ Arg-Asp-Leu-Tyr $\left.{ }^{583}\right)$ in TG2 are shown in a ball-and-stick model (upper panel) and in a space-filled model (lower panel).

tryptophan residue at position 332 (which is flanked between two naturally occurring mutations in TG2) has been found to significantly reduce GTP binding.

In summary, the data presented here demonstrate that naturally occurring mutations in TG2 differentially affect transamidation, kinase, and G-protein functions of TG2. This would imply that transamidation, kinase, and G-protein functions of TG2 are associated with each other and regulated in a coordinated manner. Furthermore, our data indicate that various functions of TG2 are activated in a sequential manner during the different phases of GSIS. Reduced insulin secretion as a result of naturally occurring mutations in TG2 is most likely due to the impairment of more than one biological function of TG2.

\section{Declaration of interest}

The authors declare that there is no conflict of interest that could be perceived as prejudicing the impartiality of the research reported.

\section{Funding}

This work was supported by the Manitoba Health Research Council (MHRC) and the Canadian Institutes of Health Research. S M is a recipient of the Manitoba Medical Service Foundation Career Development Award and S R A is supported by an MHRC Postdoctoral Fellowship.

\section{References}

Ande SR \& Mishra S 2009 Prohibitin interacts with phosphatidylinositol 3,4,5-triphosphate (PIP3) and modulates insulin signaling. Biochemical and Biophysical Research Communications 390 1023-1028. (doi:10.1016/j.bbrc.2009.10.101)

Ande SR, Gu Y, Nyomba BLG \& Mishra S 2009 $a$ Insulin induced phosphorylation of prohibitin at tyrosine114 recruits Shp1. Biochimica et Biophysica Acta 1793 1372-1378. (doi:10.1016/ j.bbamcr.2009.05.008)

Ande SR, Moulik S \& Mishra S 2009b Interaction between $O$-GlcNAc modification and tyrosine phosphorylation of prohibitin: implication for a novel binary switch. PLoS ONE 4 e4586. (doi:10.1371/journal.pone.0004586)

Antonyak MA, Jansen JM, Miller AM, Ly TK, Endo M \& Cerione RA 2006 Two isoforms of tissue transglutaminase mediate opposing cellular fates. PNAS 103 18609-18614. (doi:10.1073/pnas. 0604844103)

Bae J, Lee YS \& Jeoung D 2006 Down-regulation of transglutaminase II leads to impaired motility of cancer cells by inactivation of the protein kinase, Akt, and decrease of reactive oxygen species. Biotechnology Letters 28 1151-1158. (doi:10.1007/s10529-006-9079-6)

Baek KJ, Kang SK, Damron DS \& Im MJ 2001 Phospholipase C 81 is a guanine nucleotide exchanging factor for transglutaminase II (G $\alpha \mathrm{h})$ and promotes $\alpha 1 \mathrm{~B}$-adrenoreceptor-mediated GTP binding and intracellular calcium release. Journal of Biological Chemistry 276 5591-5597. (doi:10.1074/jbc.M008252200)

Begg GE, Holman SR, Stokes PH, Matthews JM, Graham RM \& Iismaa SE 2006 Mutation of a critical arginine in the GTP-binding site of transglutaminase 2 disinhibits intracellular cross-linking activity. Journal of Biological Chemistry 281 12603-12609. (doi:10.1074/jbc.M600146200)

Bernassola F, Federici M, Corazzari M, Terrinoni A, Hribal ML, De Laurenzi V, Ranalli M, Massa O, Sesti G, McLean WH et al. 2002 Role of transglutaminase 2 in glucose tolerance: knockout mice studies and a putative mutation in a MODY patient. FASEB Journal 16 1371-1378. (doi:10.1096/fj.01-0689com)

Brymora A, Cousin MA, Roufogalis BD \& Robinson PJ 2001 Enhanced protein recovery and reproducibility from pull-down assays and immunoprecipitations using spin columns. Analytical Biochemistry 295 119-122. (doi:10.1006/abio.2001.5215)

Bungay PJ, Owen RA, Coutts IC \& Griffin M 1986 A role for transglutaminase in glucose-stimulated insulin release from the pancreatic beta-cell. Biochemical Journal 235 269-278.

Driscoll HK, Adkins CD, Chertow TE, Cordle MB, Matthews KA \& Chertow BS 1997 Vitamin A stimulation of insulin secretion: effects on transglutaminase mRNA and activity using rat islets and insulinsecreting cells. Pancreas 15 69-77. (doi:10.1097/00006676199707000-00010)

Fesus L \& Piacentini M 2002 Transglutaminase 2: an enigmatic enzyme with diverse functions. Trends in Biochemical Sciences 27 534-539. (doi:10.1016/S0968-0004(02)02182-5)

Fofana B, Yao XH, Rampitsch C, Cloutier S, Wilkins JA \& Nyomba BL 2010 Prenatal alcohol exposure alters phosphorylation and glycosylation of proteins in rat offspring liver. Proteomics 10 417-434. (doi:10.1002/pmic.200800969)

Gauthier BR, Wiederkehr A, Baquié M, Dai C, Powers AC, Kerr-Conte J, Pattou F, MacDonald RJ, Ferrer J \& Wollheim CB 2009 PDX1 deficiency causes mitochondrial dysfunction and defective insulin secretion through TFAM suppression. Cell Metabolism 10 110-118. (doi:10.1016/j.cmet.2009.07.002) 
Gentile V, Davies PJ \& Baldini A 1994 The human tissue transglutaminase gene maps on chromosome $20 \mathrm{q} 12$ by in situ fluorescence hybridization. Genomics 20 295-297. (doi:10.1006/geno.1994.1170)

Ghosh S, Watanabe RM, Hauser ER, Valle T, Magnuson VL, Erdos MR, Langefeld CD, Balow J Jr, Ally DS, Kohtamaki K et al. 1999 Type 2 diabetes: evidence for linkage on chromosome 20 in 716 Finnish affected sib pairs. PNAS 96 2198-2203. (doi:10.1073/ pnas.96.5.2198)

Iismaa SE, Chung L, Wu MJ, Teller DC, Yee VC \& Graham RM 1997 The core domain of the tissue transglutaminase Gh hydrolyzes GTP and ATP. Biochemistry 36 11655-11664. (doi:10.1021/bi970545e)

Ji L, Malecki M, Warram JH, Yang Y, Rich SS \& Krolewski AS 1997 New susceptibility locus for NIDDM is localized to human chromosome 20q. Diabetes 46 876-881. (doi:10.2337/diabetes.46.5.876)

Johnson JD 2007 Pancreatic beta-cell apoptosis in maturity onset diabetes of the young. Canadian Journal of Diabetes 31 67-74.

Kajio H, Olszewski S, Rosner PJ, Donelan MJ, Geoghegan KF \& Rhodes CJ 2001 A low-affinity $\mathrm{Ca}^{2+}$-dependent association of calmodulin with the Rab3A effector domain inversely correlates with insulin exocytosis. Diabetes 50 2029-2039. (doi:10.2337/diabetes.50.9.2029)

Kasai K, Ohara-Imaizumi M, Takahashi N, Mizutani S, Zhao S, Kikuta T, Kasai H, Nagamatsu S, Gomi H \& Izumi T 2005 Rab27a mediates the tight docking of insulin granules onto the plasma membrane during glucose stimulation. Journal of Clinical Investigation 115 388-396. (doi:10.1172/JCI22955)

Lacy PE \& Kostianovsky M 1967 Method for the isolation of intact islets of Langerhans from the rat pancreas. Diabetes 16 35-39.

Lai T-S, Bielawska A, Peoples KA, Hannun YA \& Greenberg CS 1997 Sphingosylphosphocholine reduces the calcium ion requirement for activating tissue transglutaminase. Journal of Biological Chemistry 272 16295-16300. (doi:10.1074/jbc.272.26.16295)

Lee J, Nguyen K, Mishra S \& Nyomba BL 2010 Prohibitin is expressed in pancreatic $\beta$-cells and protects against oxidative and proapoptotic effects of ethanol. FEBS Journal 277 488-500. (doi:10.1111/j.1742-4658.2009.07505.x)

Merglen A, Theander S, Rubi B, Chaffard G, Wollheim CB \& Maechler P 2004 Glucose sensitivity and metabolic-secretion coupling studied during two-year continuous culture in INS-1E insulinoma cells. Endocrinology 145 667-678. (doi:10.1210/en.2003-1099)

Mishra S \& Murphy LJ 2004 Tissue transglutaminase has intrinsic kinase activity: identification of transglutaminase 2 as an insulin-like growth factor binding protein-3 kinase. Journal of Biological Chemistry 279 23863-23868. (doi:10.1074/jbc.M311919200)

Mishra S, Saleh A, Epsino P, Davie J \& Murphy LJ 2006 Phosphorylation of histones by tissue transglutaminase. Journal of Biological Chemistry 281 5532-5538. (doi:10.1074/jbc.M506864200)

Mishra S, Melino G \& Murphy LJ 2007a Transglutaminase 2 kinase activity facilitates protein kinase A induced phosphorylation of retinoblastoma protein. Journal of Biological Chemistry 282 18108-18115. (doi:10.1074/jbc.M607413200)
Mishra S, Moulik S \& Murphy LJ $2007 b$ Prohibitin binds to C3 and enhances complement activation. Molecular Immunology 44 1907-1912. (doi:10.1016/j.molimm.2006.09.025)

Murthy SN, Iismaa S, Begg G, Freymann DM, Graham RM \& Lorand L 2002 Conserved tryptophan in the core domain of transglutaminase is essential for catalytic activity. PNAS 99 2738-2742. (doi:10.1073/pnas.052715799)

Nguyen KH, Yao XH, Moulik S, Mishra S \& Nyomba BL 2011 Human IGF binding protein-3 overexpression impairs glucose regulation in mice via an inhibition of insulin secretion. Endocrinology 152 2184-2196. (doi:10.1210/en.2010-1324)

Parkash J, Chaudhry MA, Amer AS, Christakos S \& Rhoten WB 2002 Intracellular calcium ion response to glucose in beta-cells of calbindin-D28k nullmutant mice and in betaHC13 cells overexpressing calbindin-D28k. Endocrine 18 221-229. (doi:10.1385/ENDO:18:3:221)

Paulmann N, Grohmann M, Voigt J-P, Bert B, Vowinckel J, Bader M, Skelin M, Jevsek M, Fink H, Rupnik M et al. 2009 Intracellular serotonin modulates insulin secretion from pancreatic $\beta$-cells by protein serotonylation. PLoS Biology 7 e1000229. (doi:10.1371/ journal.pbio.1000229)

Pinkas DM, Strop P, Brunger AT \& Khosla C 2007 Transglutaminase 2 undergoes a large conformational change upon activation. PLoS Biology 5 e327. (doi:10.1371/journal.pbio.0050327)

Porzio O, Massa O, Cunsolo V, Colombo C, Malaponti M, Bertuzzi F, Hansen T, Johansen A, Pedersen O, Meschi F et al. 2007 Missense mutations in the TG2 gene encoding transglutaminase 2 are found in patients with early-onset type 2 diabetes. Human Mutation $\mathbf{2 8}$ 1150. (doi:10.1002/humu.9511)

Siegel M \& Khosla C 2007 Transglutaminase 2 inhibitors and their therapeutic role in disease states. Pharmacology $\mathcal{E}$ Therapeutics 115 232-245. (doi:10.1016/j.pharmthera.2007.05.003)

Szypowska AA \& Burgering BM 2011 The peroxide dilemma: opposing and mediating insulin action. Antioxidants $\mathcal{E}$ Redox Signaling 15 219-232. (doi:10.1089/ars.2010.3794)

Yada T 1994 Action mechanisms of amino acids in pancreatic B-cells. In Frontiers of insulin secretion and pancreatic B cell research. Eds P Flatt and S Lenzen pp129-135 Smith-gordon:London

Zouali H, Hani EH, Philippi A, Vionnet N, Beckmann JS, Demenais F \& Froguel P 1997 A susceptibility locus for early-onset non-insulin dependent (type 2) diabetes mellitus maps to chromosome 20q, proximal to the phosphoenolpyruvate carboxykinase gene. Human Molecular Genetics 6 1401-1408. (doi:10.1093/hmg/6.9.1401)

Received in final form 29 February 2012 Accepted 6 March 2012

Made available online as an Accepted Preprint 6 March 2012 